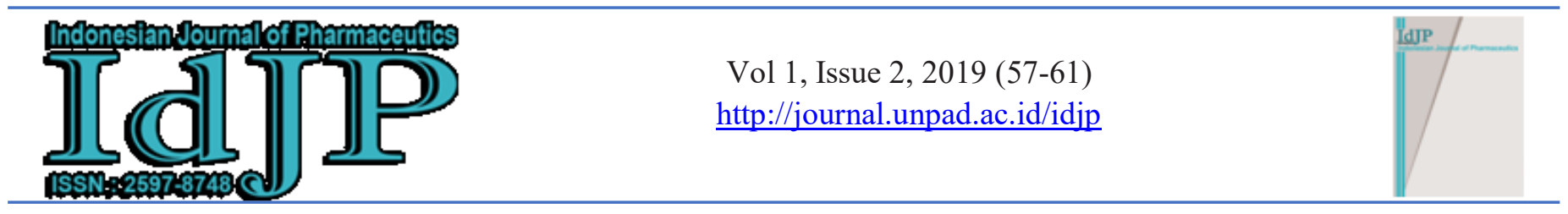

\title{
Antioxidant Activities of Muntingia calabura, Syzygium cumini, Ocimum basilicum, and Eleutherine bulbosa using DPPH Method
}

\author{
Ani Haerani ${ }^{1 *}$, Anis Yohana Chaerunisa ${ }^{1}$, Anas Subarnas ${ }^{2}$ \\ 1 Department of Pharmaceutics, Faculty of Pharmacy, Universitas Padjadjaran, Sumedang, Indonesia, \\ 45363 \\ 2 Department of Pharmacology and Clinical Pharmacy, Faculty of Pharmacy, Universitas Padjadjaran, \\ Indonesia 45363
}

Received: 15 May 2019/Revised: 20 May 2019/Acepted: 25 May 2019/Published: 13 Jun 2019

\begin{abstract}
Antioxidants are substances that can provide endogenous protection and exogenous oxidative stress by capturing free radicals. Many plants are efficacious as antioxidants, namely plants that contain polyphenols, especially flavonoids, so many are formulated as natural antioxidants. Plants such as Muntingia calabura, Syzygium cumini, Ocimum basilicum and Eleutherine bulbosa contain polyphenol compounds, especially flavonoids which are efficacious as natural antioxidants. This research aimed to study antioxidant activity derived from some potential plants using the DPPH method by calculating the IC50 value of each plant extract. This research method starts from the determination process to prove the validity of the plants used, the extraction process using the maceration method with $70 \%$ ethanol solvent, then the antioxidant activity of extracts from each plant was carried out using the DPPH method. This research starts from the determination process to ensure the correctness of the plants used, then the extraction process is carried out using the maceration method with $70 \%$ ethanol solvent. After that the antioxidant activity was determined from the four plants using the DPPH method to see the strongest IC50 value among the four plants. IC50 is the concentration of the sample to inhibit $50 \%$ of free radicals. The results of IC50 values fromethanol extract of Muntingia calabura leaves, Syzygium cumini leaves, Ocimum basilicum leaves and Eleutherine bulbosa bulbs, were 18.72; 63,84; 141.59 and $173.15 \mathrm{ppm}$. Ethanol extract of Muntingia Calabura has a smaller IC50 value of $18.72 \mathrm{ppm}$ which has a very strong and most powerful antioxidant from the ethanol extract of Syzygium cumini, Ocimum basilicum and Eleutherine bulbosa.
\end{abstract}

Keywords: Antioxidant, Muntingia calabura, Syzygium cumini, Ocimum basilicum, Eleutherine bulbosa, DPPH Method

\section{Introduction}

Antioxidants defined as molecules having ability to inhibit the oxidation of other molecules mostly caused by free radicals, therefore can reduces the damages due to oxygen $[1,2,3]$. Antioxidants can be catagorized as either synthetic or natural and both are included in formulations. Synthetic antioxidants (e.g. butylated hydroxyanisole (BHA), butylated hydroxytoluene (BHT), and propyl gallate) has been largely used for many purposes since the ease of production leading to lower prices. However, high potential health risks following a high consumption of synthetic antioxidants has been reported by some studies. Despite the high demand for synthetic antioxidants by market, concerns on natural antioxidants have been increased in the last few years and it is expected to continue and growing. There are some reasons to explain this trend. Mostly, the consumer prefer organic and natural products, since they use less additives thus it is hoped to have less side effects than synthetic ingredients[4].

Natural antioxidants has been used in the cosmetic industries including a great number of substances and extracts obtained from a variety of plants, grains and fruits, either by reducing the skin oxidative stress or protecting the skin from oxidative degradation [4].

Plants that are efficacious as antioxidants are plants that contain carotenoids and polyphenols, especially flavonoids which can be formulated as natural antioxidants in oral dosage forms such as vitamins and topicals for skin care products.

This research aims to determine the antioxidant activity of Muntingia calabura leaves, Syzygium cumini leaves, Ocimum basilicum leaves and Eleuherine bulbosa bulbs since they contain polyphenol compounds, especially flavonoids which known to have efficacious as natural antioxidants. Muntingia calabura L. contains phenolic acids and flavonoids [5]. Syzygium cumini L. contains anthocyanin, glucoside, isokuercin, kaempferol, myrisetin and high total phenolic compounds [6]. Ocimum basilicum L. contains apigenin and rosmarinic acid which can be used as anti-radical free [7]. Eleuherine bulbosa (Mill.) Urb contains three groups of compounds, namely naphtalen, naphtokuinon and anthraquinone [8].

Determination of antioxidant activity in this study 
using the DPPH method. The were conducted by DPPH method is used to obtain IC50 values from a plant extract. IC50is the concentration of the sample to inhibit $50 \%$ of free radicals. A compound is said to have very strong antioxidant activity if the IC50 value is less than $50 \mathrm{ppm}$, strong if the IC50 value is $50-100 \mathrm{ppm}$, moderate if it is $100-150 \mathrm{ppm}$ and weak if the IC50 value is $150-200 \mathrm{ppm}$ [9].

\section{Materials and Methods}

\subsection{Materials}

Muntingia calabura leaves, Syzygium cumini leaves, Ocimum basilicum leaves and Eleutherine bulbosa bulbs from Manoko plantation, Lembang, Bandung. Determination of plants is evaluated at the Laboratory of Taxonomy, Department of Biology, Faculty of Mathematics and Natural Sciences, Padjadjaran University. The chemicals used in this study include ethanol 96\% p.a (Merck), DPPH (2,2diphenyl-1-pycryl-hydrazil) (Sigma), ascorbic acid (Merck). Absorbance of sample is analyzed using UV-Vis spectrophotometer (TECAN M200Pro).

\subsection{Methods}

\subsubsection{Material collection and plant determination.}

Plant material used was obtained from the Manoko plantation, Lembang, West Java. Plants were determined at the Taxonomy Laboratory, Biology Department, Faculty of Mathematics and Natural Sciences, Padjadjaran University.

\subsubsection{Extraction}

The extraction of Muntingia calabura leaf, Syzygium cumini leaf, Ocimum basilicum leaf and Eleutherine bulbosa bulbs plant were conducted using maceration with $70 \%$ ethanol solvent for 3 times 24 hours. Liquid extract concentrated with a rotary evaporator then steamed above a water bath until constant weight of the extract. The yield of the extract can be calculated by the formula :

Rendament $(\%)=1+\frac{\text { Weight of Extract }}{\text { Weight of Simplicia }} \times 100$

\subsubsection{In vitro Antioxidant Activity Test of Extract}

a. Sample Preparation

Ethanol extracts were prepared with a stock solution of 1000 ppm. 1000 ppm stock solution is diluted to concentration $0,5,10,15,20$ and 25 ppm for Muntingia calabura L., 0, 20, 40, 60, 80 and 100 ppm for Syzigium cumini L., 0, 50, 100, 150, 200 and 250 ppm for Ocimum basilicum L. and Eleutherine bulbosa (Mill.).

b. Preparation of Comparative Solutions

Ascorbic acid was prepared with a solution of
$100 \mathrm{ppm}$. Diluted a stock solution standard to concentration $0,1,2,3,4,5$ ppm [10].

c. Preparation of DPPH solution (2,2-diphenyl-1pycryl-hydrazyl)

DPPH was weighed and dissolved in ethanol p.a at a concentration of $160 \mathrm{ppm}$ for immediate use and maintained in low temperatures and protected from light exposure[10].

d. Maximum Wavelength Determination DPPH $0.2 \mathrm{~mL}$ solution was dissolved with 0.8 $\mathrm{mL}$ ethanol with a concentration of $250 \mathrm{ppm}$, measured at 500-530 nm wavelength to obtain an absorbance of $\pm 0.2-0.8[10]$.

e. Determination of IC50 with DPPH Method The ethanol extract of Muntingia calabura leaves, Syzygium cumini leaves, Ocimum basilicum leaves and Eleutherine bulbosa bulbs were added $1 \mathrm{~mL}$ DPPH for each concentration, then sonication and incubated for 30 minutes at room temperature. The absorbance was measured at $517 \mathrm{~nm}$. The inhibition percentage was calculated using the equation [11]:

$$
\text { Inhibition }(\%)=\frac{\mathrm{Ab}-\mathrm{As}}{\mathrm{Ab}} \times 100
$$

\section{Results}

\subsection{Determination}

The results of plant determination show Muntingia calabura leaves belongs tothe Family: Muntingiaceae, Genus: Muntingia, Species: Muntingia calabura L, Indonesian name : Kersen. Syzygium cumini leaves included in the Family: Myrtaceae, Genus: Syzygium, Species: Syzygium cumini(L.) Skeels., Indonesian name : Jamblang. Ocimum basilicum leaves included in the Family: Lamiaceae, Genus: Ocimum, Species: Ocimum basilicum L,., Indonesian name : Kemangi. Eleutherine bulbosa bulbs included in the Family: Tridaceae, Genus: Eleutherine, Species: Eleutherine bulbosa (Mill.) Urb., Indonesian name : Bawangdayak.

\subsection{Extraction}

Muntingia calabura leaves extraction (250 g) was macerated with $70 \%$ ethanol solvent resulting leaf extract of 78,836 $\mathrm{g}$ (rendement $=31,53 \%$ ). Syzygium cumini leaves, Ocimum basilicum leaves and Eleutherine bulbosa bulbs extraction (100 g) was macerated with $70 \%$ ethanol solvent resulting 28,49 ; 19,$94 ; 13,24 \mathrm{~g}$ (rendement $\%=28,49 ; 19,94 ; 13,24$ \%) (Table 2 - 5 and Figure 1-4)

\subsection{Antioxidant Activity}

In this study, antioxidant activity was tested for all four plants, using the DPPH method. The principle of the DPPH method is based on measurements of capture of antioxidant capacity. DPPH is a free 
radical is stable in purple, can be reduced by the presence of antioxidant molecules resulting in changes in color from purple to yellow. The results of testing the antioxidant activity indicate IC50 values can be seen in table 6 .

Table 1. Phytochemical Screening Results of Ethanol Extracts of $M$. calabura leaves, $S$. cumini leaves, $O$. basilicum leaves and E. bulbosa bulbs.

\begin{tabular}{ccccc}
\hline Parameter & $\mathrm{Mc}$ & $\mathrm{Sc}$ & $\mathrm{Ob}$ & $\mathrm{Eb}$ \\
\hline Alkaloid & + & + & + & + \\
Flavonoid & + & + & + & + \\
Polifenol & + & + & + & + \\
Tanin & + & + & - & - \\
Saponin & + & + & + & - \\
Steroid \& Terpenoid & + & + & + & - \\
Monoterpenoid \&Seskui- & + & + & + & + \\
terpenoid & + & & & \\
Kuinon & + & + & - & + \\
\hline
\end{tabular}

Note :

$\begin{array}{ll}(+) & \text { : Identified } \\ (-) & \text { : Not Identified } \\ \mathrm{Mc} & : \text { Muntingia calabura } \mathrm{L} . \\ \mathrm{Sc} & : \text { Syzygium cumini } \mathrm{L} . \\ \mathrm{Ob} & : \text { Ocimum basilicum } \mathrm{L} . \\ \mathrm{Eb} & : \text { Eleutherine bulbosa }\end{array}$

Based on the results of phytochemical screening in the table 1 . The four plants contain compound alkaloid, flavonoid, polifenol, monoterpenoid and seskuiterpenoid.

Tabel 2. $\mathrm{IC}_{50}$ of Muntingia calabura L.

\begin{tabular}{ccc}
\hline Concentration (ppm) & Absorbance & \% Inhibition \\
\hline 0 & 0,8199 & 0 \\
5 & 0,69495 & 15,23966 \\
10 & 0,58015 & 29,24137 \\
15 & 0,4642 & 43,38334 \\
20 & 0,3598 & 56,1166 \\
25 & 0,3164 & 61,40993 \\
\hline
\end{tabular}

\section{Discussion}

Phytochemical screening was carried out on Muntingia calabura leaves extract, Syzygium cumini leaves, Ocimum basilicum leaves and Eleutherine bulbosa bulbs. Phytochemical screening aims to
Table 3. $\mathrm{IC}_{50}$ of Syzygium cumini L.

\begin{tabular}{ccc}
\hline Concentration $(\mathrm{ppm})$ & Absorbance & \% Inhibition \\
\hline 0 & 0,9244 & 0 \\
20 & 0,76795 & 16,92449 \\
40 & 0,6183 & 33,11337 \\
60 & 0,47605 & 48,50173 \\
80 & 0,3787 & 59,03288 \\
100 & 0,1959 & 78,80788 \\
\hline
\end{tabular}

Table 4. $\mathrm{IC}_{50}$ of Ocimum basilicum $\mathrm{L}$.

\begin{tabular}{ccc}
\hline Concentration $(\mathrm{ppm})$ & Absorbance & \% Inhibition \\
\hline 0 & 0,8334 & 0 \\
50 & 0,6431 & 22,83417 \\
100 & 0,52245 & 37,31102 \\
150 & 0,3534 & 57,59539 \\
200 & 0,2598 & 68,82649 \\
250 & 0,15415 & 81,50348 \\
\hline
\end{tabular}

Table 5. $\mathrm{IC}_{50}$ of Eleutherine bulbosa Merr.

\begin{tabular}{ccc}
\hline Concentration $(\mathrm{ppm})$ & Absorbance & \% Inhibition \\
\hline 0 & 0,7756 & 0 \\
50 & 0,6425 & 17,16091 \\
100 & 0,4945 & 36,24291 \\
150 & 0,40095 & 48,30454 \\
200 & 0,3235 & 58,29036 \\
250 & 0,2725 & 64,86591 \\
\hline
\end{tabular}

Table 6. IC $_{\mathbf{5 0}}$ Muntingia calabura leaves extract, Syzygium cumini leaves, Ocimum basilicum leaves and Eleutherine bulbosa bulbs

\begin{tabular}{cc}
\hline Plant Name & $\mathrm{IC}_{50}(\mathrm{ppm})$ \\
\hline Muntingia calabura & 18,72 \\
Syzygium cumini & 63,84 \\
Ocimum basilicum & 141,59 \\
Eleutherine bulbosa & 173,15 \\
\hline
\end{tabular}

determine and determine the secondary metabolites contained therein[12]. The results of phytochemical screening showed that all four plants contained alkaloid compounds, flavonoids, polyphenols, monoterpenoids and sesquiterpenoids. Compounds such as flavonoids and polyphenols are compounds that have 


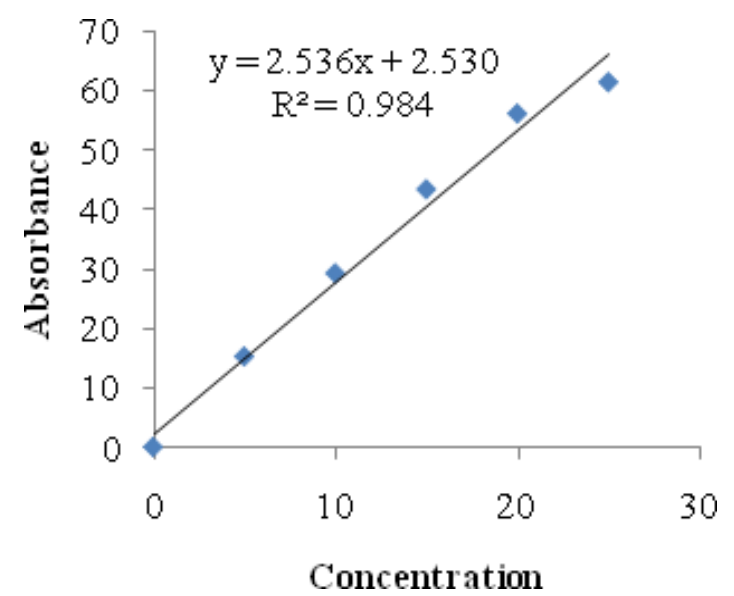

Figure 1. Curve calibration of Muntingia calabura L.

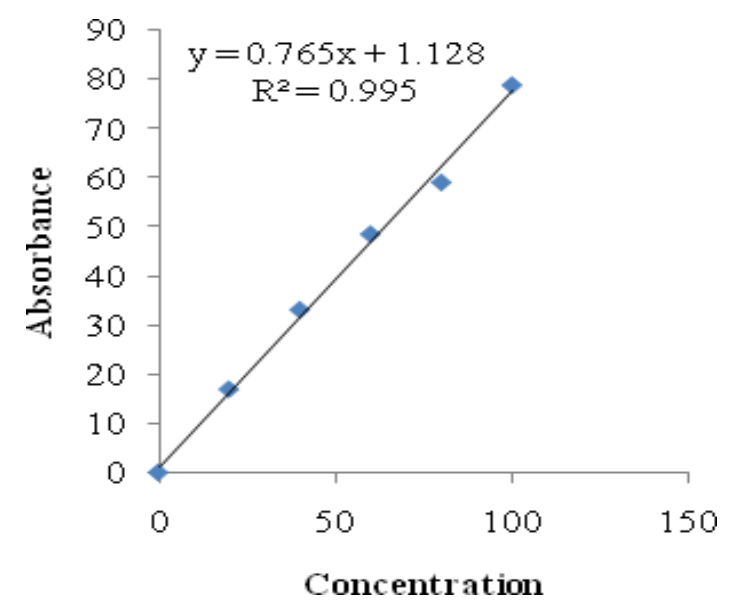

Figure 2. Curve calibration of Syzygium cumini L.

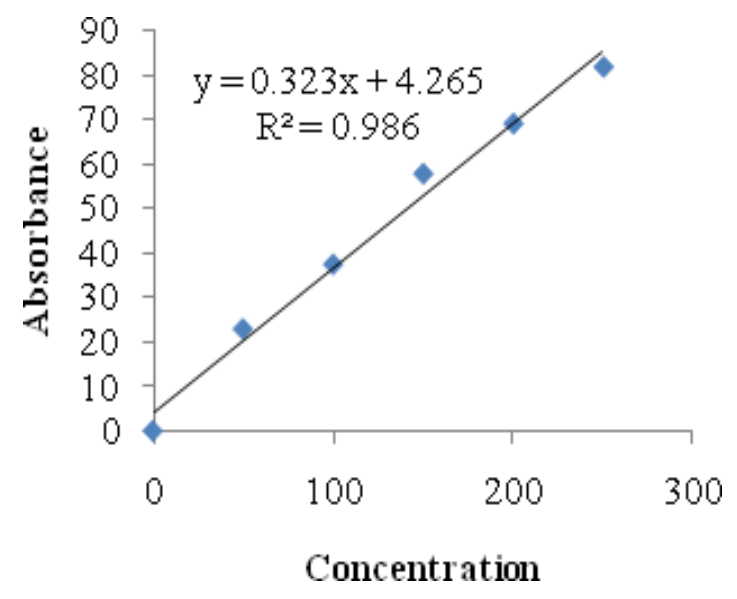

Figure 3. Curve calibration of Ocimum basilicum L.

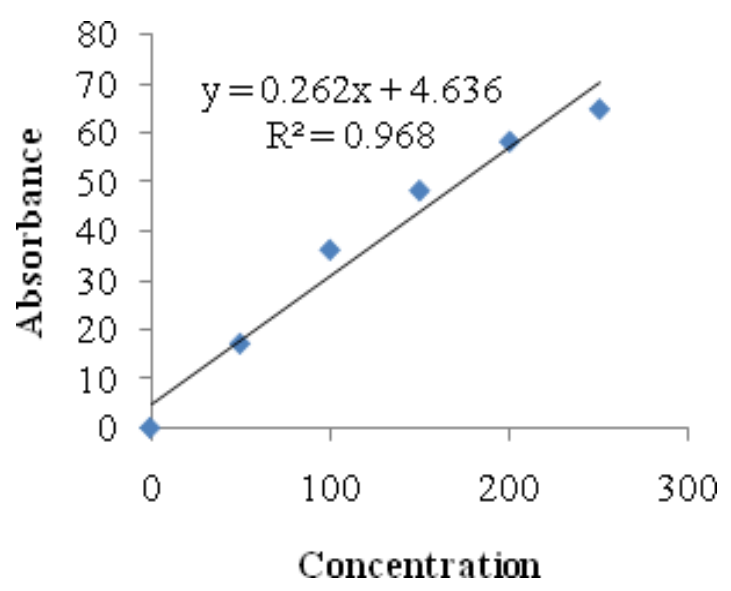

Figure 4. Curve calibration of Eleutherine bulbosa.

antioxidant activity. Based on the compound content in it, the four plants have positive antioxidant activity [13].

The anti oxidant activity test was carried out using a UV-Viss pectrophotometer. This test was conducted to determine thea bsorbance of the remaining DPPH after adding the sample. If the DPPH solution is dissolved with a compound that has antioxidant activity, there will be a decrease in the value of DPPH absorbance which is characterized by a change in color from purple to yellow after incubation for 30 minutes.

This study uses the DPPH method to obtain $\mathrm{IC}_{50}$ values from a plant extract. $\mathrm{IC}_{50}$ is the concentration of the sample to inhibit $50 \%$ of free radicals. A compound is said to have very strong antioxidant activity if the $\mathrm{IC}_{50}$ value is less than $50 \mathrm{ppm}$, strong if the $\mathrm{IC}_{50}$ value is $50-100 \mathrm{ppm}$, moderate if it is $100-150 \mathrm{ppm}$ and weak if the $\mathrm{IC}_{50}$ value is $150-200 \mathrm{ppm}$ (Zuhra et al., 2008). Based on the results of the study of $\mathrm{IC}_{50}$ Muntingia calabura leaf ethanol extract of $18.72 \mathrm{ppm}$ including very strong, the $\mathrm{IC}_{50}$ Syzygium cumini leaf value of $63.84 \mathrm{ppm}$ was strong, $\mathrm{IC}_{50}$ Ocimum basilicum leaf value was $141.59 \mathrm{ppm}$ including moderate and $\mathrm{IC}_{50}$ Eleutherine bulbosa leaf value ie 173.15 ppm including weak. Based on $\mathrm{IC}_{50}$ values produced from the four plants, it can be seen that the ethanol extract of Muntingia calabura has the strongest antioxidant activity because it has a very high content of phenolic compounds, especially flavonoids.

\section{Conclusion}

The result showed that ethanol extract of Muntingia calabura produced an $\mathrm{IC}_{50}$ value of $18.72 \mathrm{ppm}$ so it can be concluded that ethanol extract of Muntingia 
calabura leaf has the strongest and most powerful antioxidant activity between Syzygium cumini, Ocimum basilicum and Eleutherine bulbosa.

\section{References}

[1] Oresajo, C., Pillai, S., Manco, M., Yatskayer, M., and Mcdaniel, D. (2012). Antioxidants and the skin : Understanding formulation and efficacy, 25, 252-259.

[2] Allemann,I. B., and Baumann, L. A n t i oxidants Used in Skin Care Formulations. 2008;1-8.

[3] Lai-Cheong, J. E., \& McGrath, J. A. Structure and function of skin, hair and nails. Medicine (United Kingdom). 2017; 45(6): 347-351. https://doi.org/10.1016/j.mpmed.2017.03.004.

[4] Costa, R., and Santos, L. Delivery systems for cosmetics - From manufacturing to the skin of natural antioxidants. Powder Technology. 2017; 322: 402-416. https://doi.org/10.1016/j. powtec.2017.07.086.

[5] Lin, J. T., Chen, Y. C., Chang, Y.Z., Chen, T. Y., and Yang, D. J. Effective compounds in the fruit of: Muntingia calabura Linn. cultivated in Taiwan evaluated with scavenging free radicals and suppressing LDL oxidation. Food and Function. 2017; 8(4): 1504-1511. https://doi. org $/ 10.1039 / \mathrm{c} 7$ fo00059f.

[6] Ayyanar, M., and Subash-Babu, P. (2012). Syzygium cumini (L.) Skeels: A review of its phytochemical constituents and traditional uses. Asian Pacific Journal of Tropical Biomedicine, 2(3), 240-246. https://doi. org/10.1016/S2221-1691(12)60050-1.

[7] Erviana, L., Malik, A., and Najib, A. Free Antiradical Activity Test of Ethanol Extract of Basil Leaf (Ocimumbasilicum L.) Using the DPPH Method. Indonesian Fitofarmaka Journal. 2016; 3 (2): 164-168.

[8] Insanu, M., Kusmardiyani, S. dan Hartati, R. Recent Studies on Phytochemicals and Pharmacological Effects of Eleutherine Americana Merr. Procedia Chemistry. 2014;13: 221-228. https://doi.org/10.1016/j.proche.2014.12.032.

[9] Zuhra, D. Antioxidant Activity of Flavonoid Compounds from Katuk Leaves (Sauropus androgynus (L) Merr.). Journal of Sumatra Biology. . 2008; 3 (1): 10-13.

[10] Najihudin, A. Antioxidant Activity of Skin Extracts and Fractions of BatangTrengguli (Cassia fistula L) with DPPH Method. IJPST. 2017; 4 (2).

\{11] Preethi, K. et. al. In vitro antioxidant activity of extracts from fruits of Muntingia calabura Linn. from India. Pharmacognosy Journal. 2010;2(14): 11-18. https://doi.org/10.1016/ S0975-3575(10)80065-3.

[12] Septiani, S. et. al. Formulation Of Antioxidant Gel Masks from the Ethanol Extract Of Melin- jo Seeds (Gnetun gnemon Linn.). Students eJournals. 2012; 1 (1); 1- 25.

[13] Calderon-Montano. A Review On The Dietary Flavonoid Kaempferol. Medical Chemistry. 2011; 11:298-344. http://doi. org/10.2174/13895571179 